\title{
Online and offline social participation and social poverty traps. Can social networks save human relations?
}

\author{
Angelo Antoci ${ }^{1}$ \\ University of Sassari and CRENoS \\ Fabio Sabatini ${ }^{2 *}$ \\ Sapienza University of Rome and HSE, Russia \\ Mauro Sodini ${ }^{3}$ \\ University of Pisa
}

\begin{abstract}
In this study, we develop an evolutionary game model to analyse how human relations evolve in a context characterised by declining face-to-face interactions and growing online social participation. Our results suggest that online networks may constitute a coping response allowing individuals to "defend" their social life from increasing busyness and a reduction in the time available for leisure. Internet-mediated interaction can play a positive role in preventing the disruption of ties and the weakening of community life documented by empirical studies. In this scenario, the digital divide is likely to become an increasingly relevant factor of social exclusion, which may exacerbate inequalities in well-being and capabilities.
\end{abstract}

Keywords: social participation; online networks; social capital; well-being; digital divide. Jel classification: C73, D85, O33, Z13.

${ }^{1}$ Department of Economics and Business, University of Sassari, Italy. E-mail: antoci@uniss.it.

2 Department of Economics and Law, Sapienza University of Rome, Italy, and Laboratory for Social Comparative Research, National Research University Higher School of Economics, Russia.

* Corresponding author. Postal address: Università di Sassari, Dipartimento di Scienze Economiche e Aziendali, Via Muroni 25, 07100, Sassari, Italy.

${ }^{3}$ Department of Economics and Management, University of Pisa, Italy. E-mail: m.sodini@ec.unipi.it. 


\section{Introduction}

Economic development and technological progress continuously and profoundly transform our way of living. Recently, the advent of the Internet and online networks has made economic and cultural changes even more radical and rapid, causing a major shift towards new types of social interaction. Studies in the social capital literature have documented two stylised facts: first, indicators of social participation declined in the years that preceded the social networking revolution (Bartolini et al., 2013; Costa \& Kahn, 2003; Putnam, 2002; Sarracino, 2010). Second, in the last five years, the success of social networking sites (SNSs) has resulted in a steep rise in online social participation (Duggan \& Brenner, 2013; Smith, 2013). Despite the immensity of these transformations, we still lack a systematic theoretical analysis of the role of online interactions in the evolution of human relations. It is also not clear whether Internet usage and SNSs may accelerate the decline in social participation, or if they offer a way to support social relationships against the threats posed by the disruption of ties and the weakening of community life documented by empirical studies.

In this paper, we draw on the empirical literature on social capital and computermediated communication to develop a theoretical framework for an analysis of how human relations may evolve in a context characterised by declining face-to-face interactions and growing online social participation. More specifically, we aim to deepen our understanding of 1) the circumstances that may exacerbate the decline in social participation; 2) the extent to which Internet-mediated interaction can help in preventing "social poverty traps" (Antoci et al., 2007); and 3) how the decline in social participation affects the relative performance of the different types of participation.

In our framework, agents can choose to participate socially or to withdraw from social relations, or at least reduce them to the minimum, in order to devote all their available time to work. Following Antoci et al. (2012a, 2013a), we assume that individuals who participate socially develop interactions in two ways: 1) using a "social networking strategy" (hereafter SPN, Social Participation through online Networks), within which social participation takes place both by means of online networking and face-to-face interactions. This strategy entails different degrees of Internet-mediated interaction according to individual preferences and the characteristics of their reference groups: in general, we think of SPN agents as individuals who develop social ties online at their convenience-for example, by staying in touch with friends and acquaintances, or interacting with unknown others, through SNSs - and meet their contacts in person whenever they want or have time. On the other hand, at the extreme end of this strategy, SPN agents can develop an entire social life online, as in the case of Japanese bikikomorit. These agents will never physically

\footnotetext{
${ }^{4}$ The Japanese term bikikomori refers to young people who have withdrawn from social life and have had no relationships outside of the family for a period of more than six months. After its rise in Japan, this phenomenon has been increasingly observed in other developed and developing countries (Kato et al., 2012). Hikikomoris do not work or participate in any form of education and frequently remain in their homes for protracted periods of time-sometimes for several years. From a psychological perspective that has long dominated public thinking in Japan, bikikomoris suffer from a cognitive malfunction. The sociological perspective, however, advances a more interesting interpretation of the phenomenon, as a form of anomie related to the nature of family relations and a breakdown in social
} 
meet their Facebook friends. 2) As an alternative, socially participating individuals can choose not to use Internet-mediated communication and to develop an entire social life through face-to-face encounters. We call this strategy SPF (Social Participation through Face-to-face encounters). These strategies can be seen as two alternative technologies of social participation, represented by vectors $\left(s_{1}, f_{1}\right)$ and $\left(s_{2}, f_{2}\right)$, where $s_{1}$ and $s_{2}$ are the time devoted to online social participation by individuals respectively playing the SPN and the $S P F$ strategy and $f_{1}$ and $f_{2}$ represent the time devoted to face-to-face social participation by SPN and SPF players respectively, $s_{1}>s_{2}=0, f_{2}>f_{1} \geq 0$ and $s_{1}+f_{1}=s_{2}+f_{2}$.

Unlike Antoci et al. (2012a, 2013a), we specifically consider the choice of social isolation by agents who prefer to devote all their time to work and to forms of private consumption $^{5}$ that do not entail any significant relationships. We call this third strategy NSP (No Social Participation). It is worth noting that, in our framework, this withdrawal from social relations does not imply retirement from work (as for bikikomori). In an NSP agent's way of life, social relations are kept to a necessary minimum, and on-the-job interactions do not entail the formation of friendships. NSP individuals tend to replace relational goods (e.g. playing a match on a football field with 21 friends) with material goods (e.g. playing a virtual match at home on a PlayStation) in their consumption choices.

The analysis shows that, depending on the configuration of payoffs, the state where all individuals play NSP can be locally attractive, i.e. it constitutes a social poverty trap where relational goods are produced and consumed in an extremely small amount and nobody participates in social activities. However, if the social networking strategy is rewarding enough in respect to the withdrawal from participation, then the state where all agents choose NSP becomes a saddle point. In this case, the use of the Internet for preserving and developing social ties avoids the social poverty trap, and the community reaches a steady state where all agents adopt the SPN strategy (which, under a certain configuration of payoffs, may also be globally attractive). This state, however, may be Pareto-dominated by the alternative state where all agents play $S P F$, and can therefore be viewed as a second-best scenario.

Our results suggest that the "SPN way of life" may be interpreted as a coping response with which agents "react" to increasing busyness, a reduction in the time available for leisure, and the cultural and relational impoverishment of the social environment. From this point of view, this paper proposes a framework to better understand results from the

and labour opportunity structures. In other words, the phenomenon can also be viewed as a reaction to the "relational poverty" of the social environment and to the lack of proper opportunities of social and labour participation (Furlong, 2008). According to Kaneko (2006), bikikomoris may be understood to be reacting to time pressures and role performances in modern societies. Before the advent of online networks, bikikomoris had no relevant social interaction. With the advent of the Internet, psychologists have observed resurgence in the social relationships of bikikomoris, who generally tend to have numerous online interactions with others (Kato et al., 2012). The case of bikikomoris will be useful for explaining our assumptions in Section 3.

5 The literature on relational goods distinguishes private consumption that can be enjoyed alone without the inclusion of any significant social interaction, and relational consumption, which can be enjoyed only if shared with others (Gui \& Stanca, 2010; Gui \& Sugden, 2005; Uhlaner, 1989). 
empirical studies finding a complementarity between online and offline interactions, which suggested that forms of Internet-mediated communication can play a crucial role in preventing the distuption of ties and the weakening of community life (Ellison et al., 2007; Sabatini and Sarracino, 2014). This argument implies that individuals who do not use the Internet (for example, because they do not have broadband access) may increasingly face problems of social integration. In this scenario, the digital divide is likely to become an important factor in social exclusion, which may exacerbate inequalities in well-being as well as capabilities. The literature has shown that social interactions and the accumulation of social capital positively influence subjective well-being (Becchetti et al., 2008; Bruni \& Stanca, 2008), health (D’Hombres et al., 2010; Yamamura, 2011a), education (Yamamura, 2011b; Misra et al., 2013), employability (Fugate et al., 2004; McDonald, 2011), economic welfare and social mobility (Degli Antoni, 2009; Yamamura, 2012), entrepreneurship (Alexy et al., 2012; Santarelli \& Tran, 2013), access to credit (Shoij et al., 2012).

The outline of the paper is as follows. Section 2 surveys the related literature. Section 3 describes our evolutionary game model. Section 4 analyses the dynamics of the model. Section 5 is devoted to a well-being analysis. The paper closes with some concluding remarks and implications for future research, followed by a mathematical appendix.

\section{Related literature}

In his best-seller Bowling Alone, Robert Putnam (2000) draws on various sources to document that a decline in social participation measures—such as membership in formal organizations, the intensity of members' participation, informal social connectedness, and interpersonal trust-began in the United States in the 1960s and 1970s with a sharp acceleration in the 1980s and 1990s.

The "decline of community life thesis" (Paxton, 1999, p. 88) advanced by Putnam prompted a number of subsequent empirical tests. Based on General Social Surveys (GSS) data for the period 1975-94, Paxton (1999) finds some decline in the general measure of social capital (given by a combination of trust and membership in associations), a decline in interpersonal trust, and no decline in associations. Costa and Kahn (2003) use a number of different sources to assess the development of social capital in the United States since 1952 by evaluating trends in participation and community life. The authors argue that the rise in female labour force participation and income inequality are two of the primary explanations for the decline in social capital, as measured by the indicators of volunteering, membership in organizations and entertainment with friends and relatives. Bartolini et al. (2013) use GSS data to investigate the evolution of social connections-measured through membership in Putnam and Olson groups ${ }^{6}$ and the indicators of perceived trustworthiness, helpfulness and

${ }^{6}$ Following Knack and Keefer (1997), the literature generally distinguishes two types of formal organisations, labelled "Olsonian" and "Putnam-esque" associations. Olson groups are those associations with redistributive goals that lobby for the protection of their members' interests, possibly against the interests of other groups (Olson 1965, 1982). Examples of this type of organisation are professional and entrepreneurial associations, trade unions and associations for the protection of consumers' rights. Putnam groups are those associations least likely to act as "distributional coalitions but which involve social interactions that can build trust and cooperative 
fairness, and confidence in institutions in the United States between 1975 and 2002, finding that they generally show a declining trend.

Apart from the United States, there seems to be a common pattern of declining trust, political participation and organizational activity across industrialised democracies during the 1980s and 1990s, with the exception of China, Japan, Korea and the Scandinavian countries (Chen \& Gao, 2013; Lee, 2008; Leigh, 2003; Listhaug \& Grønflaten, 2007). Declining trends of one or more dimensions of social capital have been documented for England and Wales over the period 1972-1999 (Li et al., 2003), Great Britain over 19802000 (Sarracino, 2010) and Australia over 1960-1990 (Cox, 2002) 7 .

In Bowling Alone, Putnam (2000) discusses three main explanations for the decline in American social capital: 1) the reduction in the time available for social interaction-related to the need to work more, to the rise in labour flexibility and to the expansion in commuting time; 2) the rise in mobility of workers and students; and 3) technology and mass media.

In the last decade, Putnam's claims have found support in a number of studies investigating the effect exerted on various dimensions of social connectedness by the rise in working time (Bartolini \& Bilancini, 2011), labour mobility (Routledge \& von Ambsberg, 2003), urban sprawl and commuting (Besser et al., 2008; Wellman, 2001) ${ }^{8}$, the psychological distress related to the need to satisfy society's expectations (Kaneko, 2006) and to the social poverty of the surrounding environment, which can prompt individuals to pursue social isolation, as in the case of Japanese bikikomoris (Furlong, 2008).

As for the third argument, the role of technology and media in the evolution of social interaction is widely debated in the literature. Putnam advanced the hypothesis that technological progress may be partially responsible for the erosion of American social capital at the end of the 1990s. This hypothesis was formulated just a few years before the "explosion" of the Internet and online networks. The author's explanation of the possibly negative role of technology was centred on the socially detrimental effects of television and other forms of "private" entertainment, such as video games. This argument found support

habits" (Knack \& Kefeer, 1997, p. 1273). Examples of this type of organization are cultural circles, sport clubs, youth associations (e.g. scouts) and religious organisations.

7 Despite the many studies documenting the decline in social participation, the overall evidence still seems to be non-conclusive. A number of empirical studies have found conflicting results on the trends of different indicators of social capital, and the Bowling Alone thesis has been variously characterised as plainly wrong, pessimistic or traditional (Stolle \& Hooghe, 2005). Worms (2000) and Van Ingen and Dekker (2011) argue that the decline in associational participation may be related to a process of "informalisation" of social activities. In his cross-country analysis of social capital trends, Sarracino (2010) finds that in most Western European countries, several measures of connectedness experienced a growth over the period 1980-2000.

8 There is different evidence on the social effects of commuting outside of the United States. In countries where cities are, on average, significantly smaller than in the U.S., Putnam's thesis seems not to be supported. A Swiss study by Viry et al. (2009) concludes that while commuting decreases the availability of emotionally bonding social capital in the form of supportive strong ties, it could provide increased opportunities for developing bridging social capital and weak ties. Wollebaeck and Stromsnes (2010) do not find evidence of a negative effect of commuting on civic engagement or connectedness in Norwegian cities. 
in several empirical studies proving the negative influence of television on social relations (Bruni \& Stanca, 2006, 2008).

All the studies mentioned above exclusively refer to face-to-face interactions and completely disregard online participation. However, in the past few years, Internet-mediated interaction has literally revolutionised individuals' social lives. In contrast to the early age of the Internet, when being connected was predominantly an individual entertainment activity like watching TV or reading newspapers, today, the use of the Web is strongly related to participation in SNSs, which in turn entails a variety of forms of engagement in social activities.

According to the Pew Research Center (PRC) Internet \& American Life Project Post-Election Survey, as of December 2012, 67\% of U.S. Internet users were active on SNSs (67\% use Facebook, 16\% use Twitter, 15\% use Pinterest and 13\% use Instagram). More than four-fifths of online young adults (aged 18-29) and 77\% of middle-aged adults (30-49) use SNSs (Duggan \& Brenner, 2013). According to a survey conducted by Princeton Survey Research Associates International in November 2010, among a sample of 2,255 adults, SNSs are used increasingly to keep up with close social ties; the average user of an SNS has more close ties and is half as likely to be socially isolated as the average American; and Facebook users are more trusting than others, have more close relationships and are much more politically engaged than the average American. Internet users get more support from their social ties than those who do not use the Internet, Facebook users get the most support and Facebook seems to play a crucial role in reviving "dormant" relationships (Brenner, 2013; Hampton et al., 2011). Almost half of Internet users create and share original content online. As of August 2012, 46\% of adult users post original photos or videos online that they themselves have created (Brenner, 2013). Sharing is also a way to keep loved ones posted on personal experiences, which proves particularly effective, for example, for workers and students living away from home. In December 2010, U.S. Internet users were found to be more likely than others to be active in some kind of voluntary group or organization: $80 \%$ of American Internet users participated in groups, compared to $56 \%$ of non-Internet users. Moreover, social media users are even more likely to be active: $82 \%$ of social network users and $85 \%$ of Twitter users are group participants (Rainie et al., 2011).

These figures suggest to mitigate the fear of social isolation that the common wisdom generally associates with intense Internet usage. Several authors from different fields have begun to empirically analyse how participation in SNSs affects human relations. The findings of this strand of the literature support the hypothesis that online interactions play a role in the preservation and development of social ties against the threats posed by the weakening of community life and the erosion of the stock of social capital.

SNSs have been claimed to support the strengthening of bonding and bridging social capital (Lee, 2013; Pénard \& Poussing, 2010; Steinfield et al., 2008), children's social activities (Bauernschuster et al., 2011) and the social integration and well-being of the elderly (Näsi et al., 2012; Russel et al., 2008), to allow the crystallization of weak or latent ties that might otherwise remain ephemeral (Ellison et al., 2007; Haythornthwaite 2005), to help users to cope with social anxiety and negative moods associated with loneliness (Clayton et al., 2013; Grieve et al., 2013; Morahan-Martin \& Schumaker, 2003), to support teenagers' selfesteem, encouraging them to relate to their peers (Ellison et al., 2011; Trepte \& Reinecke, 2013), and to promote civic engagement and political participation (Campante et al., 2013; 
Gil de Zuniga, 2012; Kittilson \& Dalton, 2011; Zhang et al., 2010)99.

Drawing on survey data from a random sample of 800 undergraduate students, Ellison et al. (2007) find that certain types of Facebook use can help individuals accumulate and maintain bridging social capital. Their results support the hypothesis that the social network helps students to overcome the barriers to participation so that individuals who might otherwise shy away from initiating communication with others are encouraged to do so through the Facebook infrastructure. In the authors' words, highly engaged users are using Facebook to "crystallize" relationships that might otherwise remain ephemeral.

Steinfield et al. (2008) analysed panel data from two surveys on Facebook users conducted a year apart at a large U.S. university. Intensity of Facebook use in year one strongly predicted bridging social capital outcomes in year two, even after controlling for measures of self-esteem and satisfaction with life. The authors suggest that Facebook affordances help reduce barriers that students with lower self-esteem might experience in forming the kinds of large, heterogeneous networks that are sources of bridging social capital. However, the literature on Facebook suggests that the social network-and, more generally, Internet-mediated communication-serves more to preserve relations among offline contacts than to activate latent ties or create connections with strangers (Bauernschuster et al., 2011; Ellison et al., 2007; Pénard \& Poussing, 2010). In one of the rare economic studies on the topic, Pénard and Poussing draw on data from the 2002 wave of the European Social Survey (ESS) from Luxembourg to find that people who already have a large stock of social capital are more likely to use the Internet to foster social relationships. In a recent paper based on data drawn from the 2008 section of the German SocioEconomic Panel and confidential data provided by Deutsche Telekom, Bauernschuster et al. (2011) find that having broadband Internet access at home has positive effects on an individual's frequency of visiting theatres, the opera and exhibitions, and on the frequency of visiting friends. Exploring a sub-sample of children aged 7 to 16 living in the sampled households, the authors further find evidence that having broadband Internet access at home increases the number of children's out-of-school social activities, such as playing sports, taking ballet, music or painting lessons, or joining a youth club.

More recently, Sabatini and Sarracino (2014) used data drawn from the Italian

\footnotetext{
${ }^{9}$ It is worth noting that part of the literature does not agree with the above reported claims about the beneficial effects of Internet-mediated interaction on social capital. Early sociological studies on computer-mediated communication shared the fear that the Internet would cause a progressive reduction in social interactions. The main argument shared by Internet sceptics was based on the presumption that the more time people spend using the Internet during leisure time, the more time is detracted from social activities (Gershuny, 2003; Katz et al., 1998, 2001; Kraut et al., 1998; Nie \& Erbring, 2000; Nie et al., 2002). Studies emphasising the possibly negative correlation between Internet usage and sociability date back to just shortly before the explosion of online networking, which, in our view, has made their results anachronistic. Today, sceptic authors warn that, beyond a certain threshold, the development of human relationships by the exclusive means of online interactions may prevent users from enjoying those emotional benefits normally associated with faceto-face interactions (see, for example, Lee et al., 2011). A survey of the literature accurately describing the different positions on the role of Internet-mediated interaction in the accumulation of social capital is included in Antoci et al. (2013).
} 
Multipurpose Household Survey to analyse the impact of participation in social networking sites such as Twitter and Facebook and in chats, forums, and newsgroups, on "physical" social participation. The authors find that online participation is significantly and positively associated with the frequency of face-to-face meetings with friends and acquaintances, even after controlling for endogeneity bias.

In this paper, we suggest a theoretical framework for analysing the complementary role of offline (or face-to-face) and online interactions in the evolution of social participation implicitly suggested by the above-mentioned studies. Our contribution to this on-going debate consists in the development of an evolutionary game model analysing how human relations may evolve in a context potentially characterised by declining face-to-face interactions and growing online social participation.

\section{The evolutionary game model}

Let us assume that, in each period of time $t$, individuals play a one-shot population game (i.e. all agents play the game simultaneously) and that they have to choose (ex ante) one of the strategies we briefly introduced above:

1) "No social participation" (NSP)

2) "Social participation with FF-interactions" (SPF)

3) "Social participation with SN-interactions" (SPN)

As explained in the introduction, the NSP strategy entails withdrawal from every unnecessary social interaction. NSP agents devote all their time to work and/or to forms of private consumption, i.e. the consumption of goods that can be enjoyed alone. More specifically, following Antoci et al. (2012b), we assume that material products may replace relational goods, or at least may be used to compensate for the lack of human interaction, when the social environment has few opportunities for participation.

The SPF strategy entails only physical encounters and excludes any computermediated interaction.

With the SPN strategy, on the other hand, individuals participate socially through both online interactions and face-to-face encounters. In the SPN way of living, online interactions result in a certain degree of physical encounter as a by-product. This amount may be very limited; in this case, the social participation of individuals choosing SPN basically consists of online contacts with peers they will never meet in person. Or, by contrast, SPN agents may use online communication exclusively as a means to improve their face-to-face sociability. The empirical literature summarised in Section 2 shows that, in most cases, instant messaging, and interactions through social networks, emails and other kinds of Internet-mediated communication are preparative and instrumental to physical interactions (Ellison et al., 2007, 2011; Gil de Zuniga, 2012; Steinfield et al., 2008). In the latter case, it would seem reasonable to assume a configuration of payoffs allowing the SPN strategy to Pareto-dominate on SPF. The share of time that SPN agents devote to physical interactions may also vary according to the characteristics of communities, reference groups and material needs. For example, if most fellow community members participate in online networks, then online contacts are more likely to be instrumental to actual interactions (Ellison et al., 2007, 2011; Hampton \& Wellman, 2003). Drawing on survey and ethnographic data from a wired 
suburb of Toronto, Hampton and Wellman (2003) show how high-speed, always-on access to the Internet, coupled with a local online discussion group, transformed and enhanced "neighbouring" through the increase in physical contacts with weaker ties, the improvement of strong ties, and the promotion of discussions and mobilization around local issues. Reference groups also play a crucial role in determining the extent to which online interactions entail physical encounters as a by-product. Online communities may regularly arrange physical meetings, as generally happens in hobby networks, such as those of photographers connected through Flickr or specialised forums (Valenzuela et al., 2009). On the other hand, reference groups may act as a deterrent to physical encounters, as in the case of hikikomoris, who avoid face-to-face interactions and develop their entire social lives online (Furlong, 2008; Kato et al., 2012). Time and distance constraints also determine the extent to which online interactions generate physical encounters. According to the computer-mediated communication literature, online networks play a vital role in the preservation of social ties in spite of distance and mismatches in the time available for leisure. In fact, online social participation favours asynchronous interactions, which allow individuals to compensate for a lack of time; one can benefit from the others' participation, for example, by reading and replying to a message or seeing a photo or a note and commenting on it, even if the person who wrote the message or shared the content is currently offline (Antoci et al., 2013).

There are a number of reasons to distinguish SPF from SPN types of social participation and to consider both of them in our model (instead of only accounting for the SPN strategy). First, the SPN strategy entails positive activation costs; a device and access to the Internet are required for computer-mediated interaction. Residents in areas with no access to broadband Internet - due for example to the lack of proper infrastructures - may be particularly disadvantaged. In addition, participation through online networks requires specific relational skills. For example, one needs to update her/his Facebook account regularly, and to reply to comments and messages. The activation costs are particularly high for specific groups, such as the elderly or economically disadvantaged individuals, who may not even consider the possibility of computer-mediated communication. As descriptive statistics clearly show, there is still a portion of the population who never use the Internet (Duggan \& Brenner, 2013).

In addition, the distinction between the two strategies allows us to point out that, even if the hypothetical scenario where all agents adopt the SPF strategy may be Paretosuperior, the possibility of playing the SPN strategy can lead to a second-best scenario, allowing society to avoid social poverty traps (i.e. those situations where all agents play NSP), as the dynamics described in this paper clearly show (see Section 4). From this perspective, the SPN strategy can be seen as a way to defend social interaction, which in respect to the $S P F$ way of participation, has the advantage of being less vulnerable to the negative social externalities caused by any increase in a share of the population adopting NSP. In addition, Internet-mediated communication fosters coordination, making the SPN strategy more "efficient". More in general, both the NSP and the SPN strategies can be seen as defensive choices through which individuals try to cope with deterioration in the social environment, for example, in terms of social participation opportunities. However, the SPN strategy creates positive social externalities, while the NSP does not (or worse, it may create negative social externalities). The case of hikikomoris can be used once again to illustrate this argument. In a world without the Internet, where the SPN strategy does not exist, bikikomori individuals 
are doomed to withdraw from social life. They become part of the NSP share of the population and their unavailability for social life negatively influences the sociability of others. With Internet-mediated interactions, i.e. the possibility of playing the SPN strategy, socially withdrawn individuals are at least available for online relationships and may positively contribute to the relational life of others. It can be argued that individuals who develop their entire social life online are likely to suffer from declining well-being and health, as studies on the detrimental effects of Facebook use suggest (Chou \& Edge, 2012; Forest \& Wood, 2012; Kim et al., 2009; Kross et al., 2013). However, a complete retirement from any form of social life is doomed to produce even worse and irreversible effects, as demonstrated by bikikomoris before the growth of online networks.

We represent the population of individuals with the vector $=\left(x_{1}, x_{2}, x_{3}\right) \in R^{3}$, where $x_{1}, x_{2}$ and $x_{3}$ indicate the shares of individuals choosing strategies NSP, SPF and $S P N$, respectively. Thus $x_{i} \geq 0$, all $i$, and $\sum_{i} x_{i}=1$; so $x$ belongs to the 2-dimensional simplex $S$.

For simplicity, we assume that the payoff functions are linear in the variables $x_{1}, x_{2}$ and $x_{3}$ :

$$
\begin{aligned}
& \Pi_{N S P}=\alpha \\
& \Pi_{S P F}=(\beta-\gamma) x_{1}+(\beta+\delta) x_{2}+\beta x_{3} \\
& \Pi_{S P N}=(\varepsilon-\eta) x_{1}+\varepsilon x_{2}+(\varepsilon+\lambda) x_{3}
\end{aligned}
$$

where $\alpha, \beta, \gamma, \delta, \varepsilon, \eta, \lambda$ are strictly positive parameters, therefore $\varepsilon-\eta<\varepsilon<\varepsilon+\lambda$ and $\beta-\gamma<\beta<\beta+\delta$. It is worth noting that our framework, though modelled as a population game, can also be seen as a game where, in each instant of time, a large amount of random pair-wise encounters takes place. In this latter context, matrix (2) represents the payoff obtained by each strategy (played by the row player) as a function of the strategy chosen by the opponent player:

$$
\begin{array}{cccc} 
& N S P & S P F & S P N \\
N S P & \alpha & \alpha & \alpha \\
S P F & \beta-\gamma & \beta+\delta & \beta \\
S P N & \varepsilon-\eta & \varepsilon & \varepsilon+\lambda
\end{array}
$$

and the functions in (1) give the expected payoffs of available strategies $\left(x_{1}, x_{2}\right.$ and $x_{3}$ are the probabilities to meet an individual choosing NSP, SPF and SPN, respectively, in random pair-wise encounters).

Notice that parameters $\beta$ and $\varepsilon$ are pivotal, in that they measure the payoffs of "mixed encounters" between SPF and SPN players. More specifically, $\beta$ is the payoff that an 
$S P F$ player receives when she/he meets an SPN player and $\varepsilon$ is the payoff received by an $S P N$ player interacting with an SPN counterpart.

In this scenario, the increase in the share $x_{1}$ of the NSP population is always undesirable (being $\varepsilon-\eta<\varepsilon<\varepsilon+\lambda$ and $\beta-\gamma<\beta<\beta+\delta$ ). By contrast, any increase in $x_{2}$ ( $x_{3}$ being constant) or in $x_{3}$ ( $x_{2}$ being constant) always improves the payoffs of both SPF and SPN.

Notice that SPN's payoffs benefit more from increases in $x_{3}$ (the share of the population playing $S P N$ ) than from increases in $x_{2}$, and $S P F$ s payoffs benefit more from an increase in $x_{2}$ (the share of the population playing $S P F$ ) than in $x_{3}$. On the other hand, if $x_{1}$ is constant, an increase in $x_{3}$ entails a reduction in the payoff of SPF and, vice versa, increases in $x_{2}$ entail a reduction in the payoff of SPN.

\section{Assumption I: $\varepsilon-\eta>\beta-\gamma$}

If all individuals adopt $\operatorname{NSP}\left(x_{1}=1\right.$ and $\left.x_{2}=x_{3}=0\right)$, the payoff of $S P N$ is higher than the payoff of SPF. In our framework, $S P N$ is, in fact, a more rewarding response (than $S P F$ ) to the impoverishment of the social environment for at least two reasons. First, SPN players can benefit from the "global" stock of social capital accumulated worldwide on the Internet. This stock $\left(K_{S}\right)$ is a public good, in that it potentially benefits whoever is connected to the Web and adopts the SPN strategy. $K_{S}$ allows instantaneous or asynchronous interactions with people who are too distant, or who have different working hours, to physically interact with our population. It is worth noting that asynchronous interactions may further help people to reconcile constraints related to mobility with the need to take care of social relationships; when individuals cannot meet in person, or conduct long-distance chats due to time differences (think, for example, of one participant who works the night shift wishing to communicate with another who works the day shift), the social capital of the Internet offers the possibility of a quality, though deferred, interaction. Second, the use of Internet-mediated interaction by SPN may allow a more efficient use of time, in that it entails a better coordination among agents and a higher diffusion of information on how to use leisure time. For example, Bauernschuster et al. (2012) find that Internet use is significantly and strongly associated with several forms of cultural consumption and satisfaction with leisure time in Germany. These mechanisms do not hold for SPF players because, in a limited though open population where everyone plays NSP and there is no "physical" participation, individuals cannot benefit from any stock of social capital (which, following Bourdieu (1980) exists only insofar as it is shared).

In our framework, the stock of social capital is exogenously given. In fact, $K_{S}$ is accumulated because of the social participation choices of all individuals using Internetmediated interaction worldwide, and cannot be influenced - not in the short run anywayby the strategies adopted by the population in our framework. In addition, it seems reasonable to assume that $K_{S}$ has a lower velocity of variation in respect to the shares $x_{1}, x_{2}$ and $x_{3}$ of the population adopting the three alternative strategies. 


\section{Assumption II: $\alpha>\beta-\gamma$}

Matrix (2) indicates that, in random pair-wise encounters, interaction with an NSP player is more rewarding for NSP players than for SPF players. In the context of a population game, on the other hand, this assumption means that, if all individuals adopt NSP, the payoff of NSP is higher than that of SPF (the payoff of SPN is described above in Assumption I). This and the following assumptions allow us to limit the analysis to the more interesting cases where the state $\left(x_{1}=1\right.$ and $\left.x_{2}=x_{3}=0\right)$ is a social poverty trap which, without the possibility of choosing the SPN strategy, would always be attractive.

\section{Assumption III: $\beta<\varepsilon+\lambda$}

If the entire population adopts SPN (i.e. $x_{3}=1$ and $x_{1}=x_{2}=0$ ), the payoff of this strategy is higher than that of SPF. In a world where everyone participates both through online networks and face-to-face encounters, not being online is necessarily less rewarding than joining the networks. On the other hand, being outside of the network (i.e. playing the $S P F$ strategy) implies an increasing relational cost. Consider, for example, an SPF-playing teenager whose classmates join Facebook. Not following them into the network may lead to the cooling of some relationships as well as to exclusion from those established through the activation of latent ties via Internet-mediated interaction.

Assumption IV: $\alpha<\beta+\delta$

As a consequence, the payoff of the NSP strategy when all individuals adopt NSP $\left(x_{1}=1\right.$ and $\left.x_{2}=x_{3}=0\right)$ is lower than the payoff of the SPF strategy when all individuals $\operatorname{adopt} \operatorname{SPF}\left(x_{2}=1\right.$ and $\left.x_{1}=x_{3}=0\right)$.

Assumption $V: \alpha<\varepsilon+\lambda$

The payoff of the NSP strategy when all individuals adopt NSP $\left(x_{1}=1\right.$ and $\left.x_{2}=x_{3}=0\right)$ is lower than the payoff of the SPN strategy when all individuals adopt $\operatorname{SPN}\left(x_{3}=1\right.$ and $\left.x_{1}=x_{2}=0\right)$.

According to matrix (2), it is more rewarding for an $S P F$ player to meet an $S P N$ player (payoff: $\beta$ ) than an NSP player (payoff: $\beta-\gamma$ ). A matching with another SPF player provides the highest possible payoff $(\beta+\delta)$. SPN players also receive the highest possible payoff when they meet their fellow players. If the SPN strategy spreads at the expense of withdrawal from social participation (NSP), than its diffusion benefits all individuals who play $S P N$ or $S P F$ (with higher benefits for the former players). 
Assumptions $I V$ and $V$, entailing that the state where all individuals adopt NSP is Pareto-dominated both by the state where everyone plays SPF and by the state where the entire population plays $S P N$, serve to restrict the analysis to the dynamics where the scenario $\left(x_{1}=1\right.$ and $\left.x_{2}=x_{3}=0\right)$ is always a "social poverty trap" (Antoci et al., 2007). This allows us to focus on the main objective of the model, i.e. to analyse how online networking may work as a "defensive choice" that reduces the risk of falling into the social poverty trap caused by a decline in social participation.

The payoff of the NSP strategy is constant (and equal to $\alpha$ ) and not subject to externalities. This strategy can thus be seen as a defensive behaviour aimed at protecting individuals from the negative consequences of a decline in social participation. As explained in Section 2, the same "protecting" role is played in the SPN way of participation. However, while NSP creates negative externalities for those who play alternative strategies, $S P N$ creates positive externalities for SPN and, to a lesser extent, also for SPF players. SPF and SPN strategies, however, generate positive externalities only insofar as the increase in the respective shares of the population $x_{2}$ and $x_{3}$ is associated with a reduction in $x_{1}$. If $x_{1}$ is constant, then any increase in $x_{2}\left(x_{3}\right)$ generates negative externalities for SPN (SPF) players.

We are aware that, in principle, the payoff of NSP may negatively depend on $x_{3}$ and $x_{2}$, for two reasons: 1 ) individuals playing NSP may be envious of those who work less and enjoy a social environment rich of participation opportunities; and 2) the adoption of NSP creates positive externalities on production.

Our choice not to account for these relationships in the model is due to our focus on the self-feeding mechanisms with which each strategy spreads among the population. In fact, each payoff grows as much as the related strategy spreads to the detriment of the other two. The assumption that the payoff of NSP negatively depends on $x_{2}$ and $x_{3}$ would not change the self-feeding nature of the diffusion mechanisms and its consequences in terms of welfare.

In our evolutionary game model, at each instant of time $t$, the distribution of strategies $\left[x_{1}(t), x_{2}(t), x_{3}(t)\right]$ determines their relative performances, which drives social evolution in the sense that the strategies that turn out to be more rewarding are imitated and, by replicating faster, manage to proliferate at the expense of the less rewarding ones. Time is continuous and the population is modelled as a continuum of players. Following Taylor and Jonker (1978), we assume that the growth rates $\dot{x}_{i} / x_{i}=\left(d x_{i} / d t\right) / x_{i}$ of the shares $x_{i}, i=$ $1,2,3$, are given by the well-known replicator equations (also see Weibull, 1995):

$$
\begin{aligned}
& \dot{x}_{1}=x_{1}\left(\Pi_{N S P}-\bar{\Pi}\right) \\
& \dot{x}_{2}=x_{2}\left(\Pi_{S P F}-\bar{\Pi}\right) \\
& \dot{x}_{3}=x_{3}\left(\Pi_{S P N}-\bar{\Pi}\right)
\end{aligned}
$$


Where $\bar{\Pi}$ represents the population-wide average payoff:

$$
\bar{\Pi}=x_{1} \cdot \Pi_{N S P}+x_{2} \cdot \Pi_{S P F}+x_{3} \cdot \Pi_{S P N}
$$

The dynamic system (3) is analysed in the Mathematical Appendix using Bomze's (1983) classification for replicator equations. In the following section, we illustrate the basic features of dynamics generated by (3).

\section{Classification of dynamics}

In this section, we describe the possible dynamic regimes that can be observed under dynamics (3), defined in the 2-dimensional simplex (see Figure 1):

$$
S=\left\{\left(x_{1}, x_{2}, x_{3}\right): x_{i} \geq 0, i=1,2,3, \sum_{i} x_{i}=1\right\}
$$

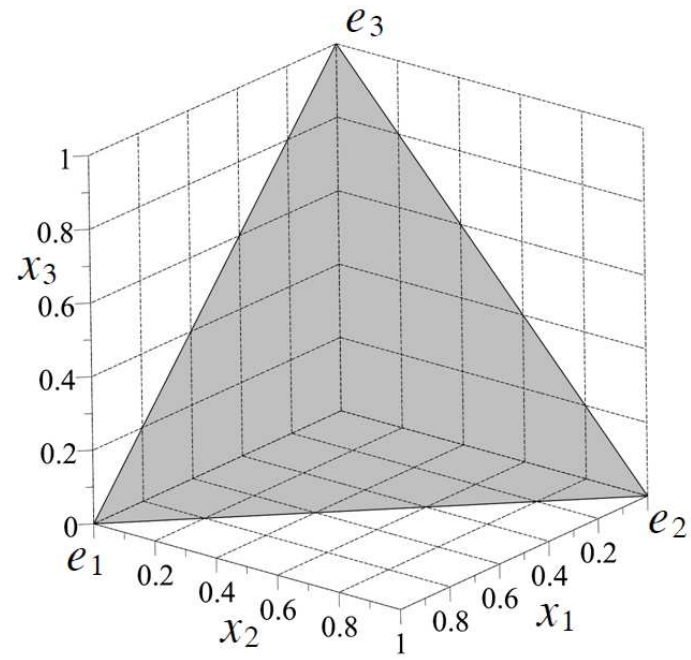

Figure 1. The 2-dimensional simplex $S$.

These regimes are illustrated in Figures 2-5. In these figures, the vertices $e_{1}=(1,0,0)$, $e_{2}=(0,1,0)$ and $e_{3}=(0,0,1)$ represent the points where, respectively, only the strategy NSP, SPF and SPN is adopted. An edge of the simplex $S$ consists of all population states in which a given (fixed) strategy is not adopted; we shall denote by $e_{i}-e_{j}$ the edge joining $e_{i}$ 
with $e_{j}$. Thus, the edges $e_{1}-e_{2}, e_{1}-e_{3}$ and $e_{2}-e_{3}$ are the edges where only strategies NSP-SPF, NSP-SPN and SPF-SPN are respectively adopted in the population of individuals.

The vertices $e_{1}, e_{2}$ and $e_{3}$ are always fixed points under replicator dynamics (3). The other fixed points of replicator dynamics are the states in which all the strategies played by a strictly positive share of individuals give the same payoffs (see Weibull, 1995). In Figures 2-5, attractive fixed points are indicated by full dots, repulsive ones by open dots and saddle points by squares.

The analysis contained in the Mathematical Appendix allows us to provide the following classification of possible dynamic regimes under dynamics (3):

Case 1: $d=\varepsilon-\alpha-\eta \geq 0$ and $e-b=\varepsilon-\beta-\delta \geq 0$

In this case, the vertex $e_{3}$, where all individuals adopt the strategy $S P N$, is globally attractive in the interior of the simplex $S$ (see Figure 2); that is, every trajectory starting from a point in the interior of $S$ approaches $e_{3}$. Notice that on the edge $e_{1}-e_{2}$, where no one plays the SPN strategy, a bi-stable dynamic regime occurs: the stationary states $e_{1}$ and $e_{2}$ are locally attractive and their basins of attraction are separated by the repelling stationary state (indicated by the open dot) lying in the interior of the edge $e_{1}-e_{2}$. Consequently, society collapses in $e_{1}$, where everyone withdraws from social participation, if the initial proportion of NSP players is high enough (and no one plays the SPN strategy). This means that, without the option of playing SPN-i.e. in the absence of online networks- the vertex $e_{1}$ acts as a social poverty trap, where the payoff of the entire population is, by assumption, lower than in $e_{2}$ (where the whole population plays $S P F$ ). The introduction of online networking (i.e. of the $S P N$ strategy) then makes $e_{1}$ a saddle point. The SPN strategy plays the same role in preventing society from falling into a social poverty trap in Case 2, described below.

Case 2: $d=\varepsilon-\alpha-\eta \geq 0$ and $e-b=\varepsilon-\beta-\delta<0$

In this case, we obtain a bi-stable dynamics regime; that is, the vertices $e_{2}$ and $e_{3}$ (where all players adopt the strategies $S P F$ and $S P N$, respectively) are locally attractive, while the other fixed points are repulsive or saddles. The basins of attraction of $e_{2}$ and $e_{3}$ are separated by the stable branch of the saddle point lying in the edge $e_{2}-e_{3}$ (see Figure 3). 


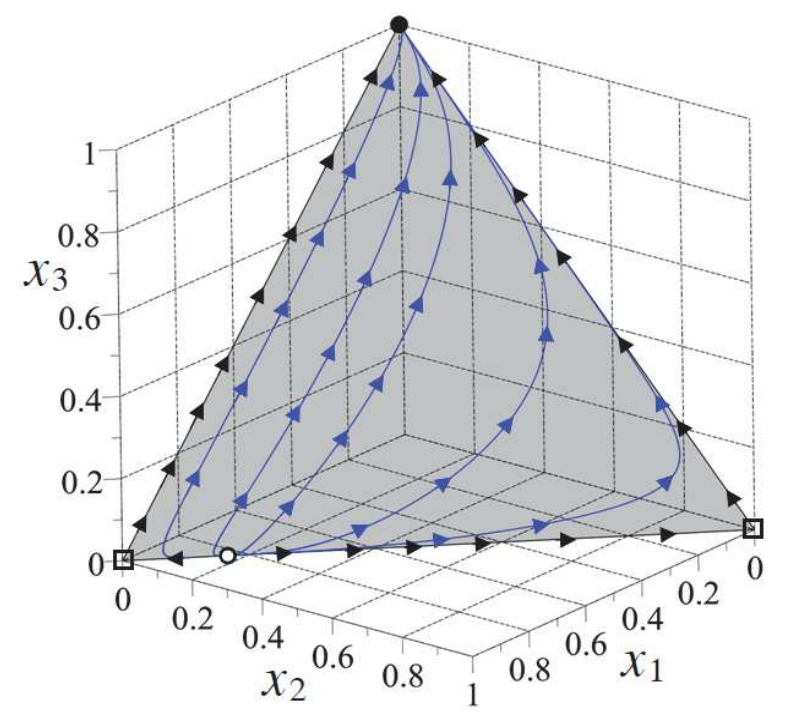

Figure 2. Case 1: The vertex $e_{3}$, where all individuals adopt the strategy SPN, is globally attractive in the interior of the simplex $S$.

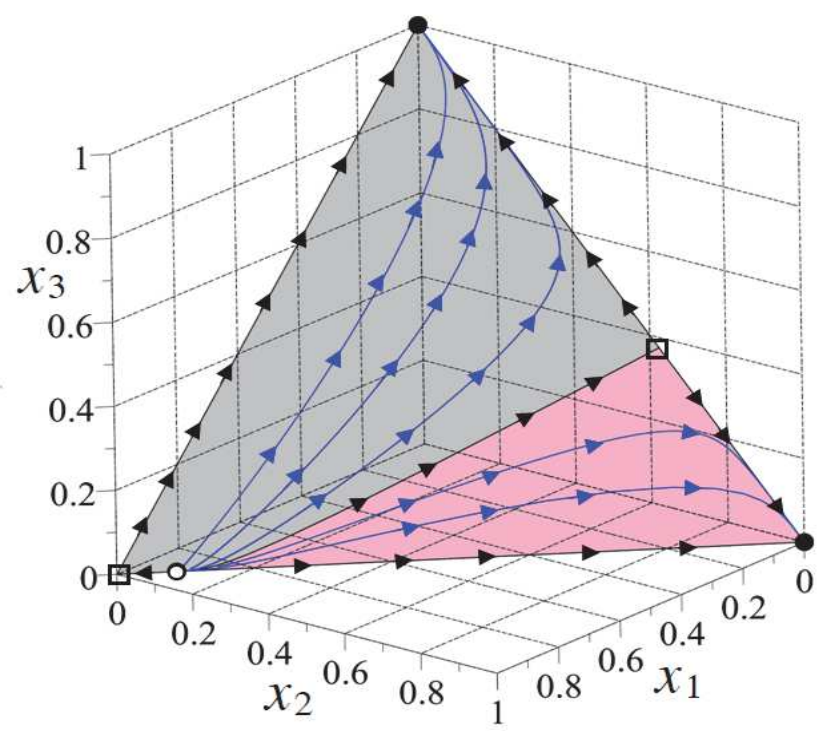

Figure 3. Case 2: The vertices $e_{2}$ and $e_{3}$, where all players adopt the strategies $S P F$ and $S P N$, respectively, are locally attractive. 
Case 3: $d=\varepsilon-\alpha-\eta<0$ and $e-b=\varepsilon-\beta-\delta \geq 0$

In this case, we also obtain a bi-stable dynamics regime. However, the attractive vertices are $e_{1}$ and $e_{3}$ (where all players adopt the strategies NSP and SPN, respectively); all the other fixed points are repulsive or saddles. According to Bomze's classification, this parameter configuration is compatible with three of the phase portraits-9, 37 and 38-shown in Bomze's paper. These phase portraits possess the common feature according to which "almost all" 10 the trajectories of system (3) approach either $e_{1}$ or $e_{3}$. Figure 4 represents the phase portrait number 9; in this figure, the basins of attraction of $e_{1}$ and $e_{3}$ are separated by the stable branches of the saddle points lying in the edges $e_{1}-e_{2}$ and $e_{1}-e_{3}$.

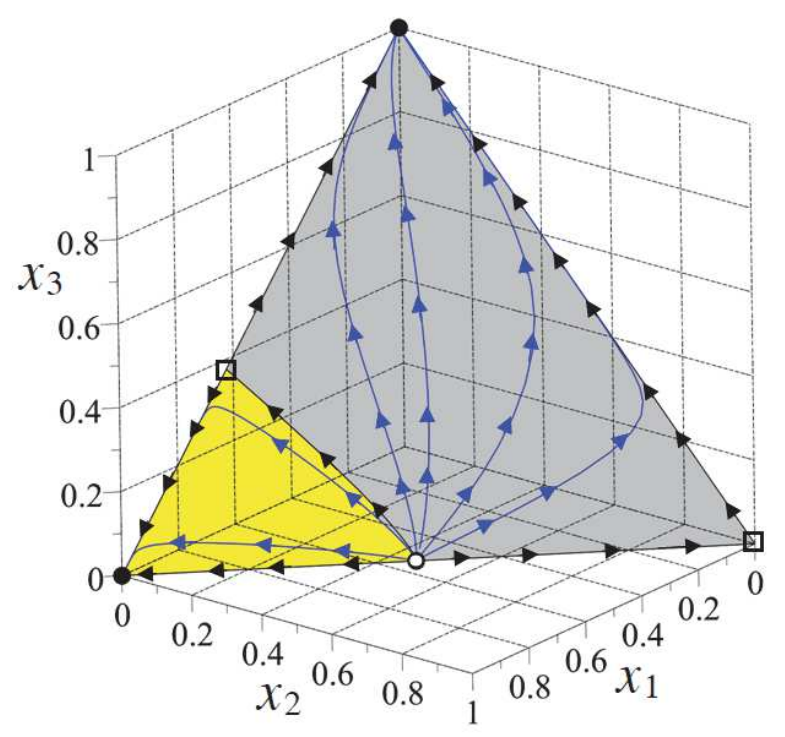

Figure 4. Case 3: The vertices $e_{1}$ and $e_{3}$, where all players adopt the strategies NSP and $S P N$, respectively, are locally attractive.

10 That is, excluding the trajectories coinciding with the other fixed points or those belonging to the stable branches of saddles. 
Case 4: $d=\varepsilon-\alpha-\eta<0$ and $e-b=\varepsilon-\beta-\delta<0$

In this case, all the fixed points in the vertices $e_{1}, e_{2}$ and $e_{3}$ are locally attractive; such parameters configuration is compatible with only two of the phase portraits illustrated in Bomze's paper-7 and 35. In these phase portraits, "almost all" (in the sense of footnote 11) trajectories approach the vertices $e_{1}, e_{2}$ and $e_{3}$. Figure 5 shows the phase portrait number 7 , where there exists a repulsive fixed point in the interior of $S$ and the fixed points in the edges are saddle points whose stable branches separate the basins of attraction of $e_{1}, e_{2}$ and $e_{3}$.

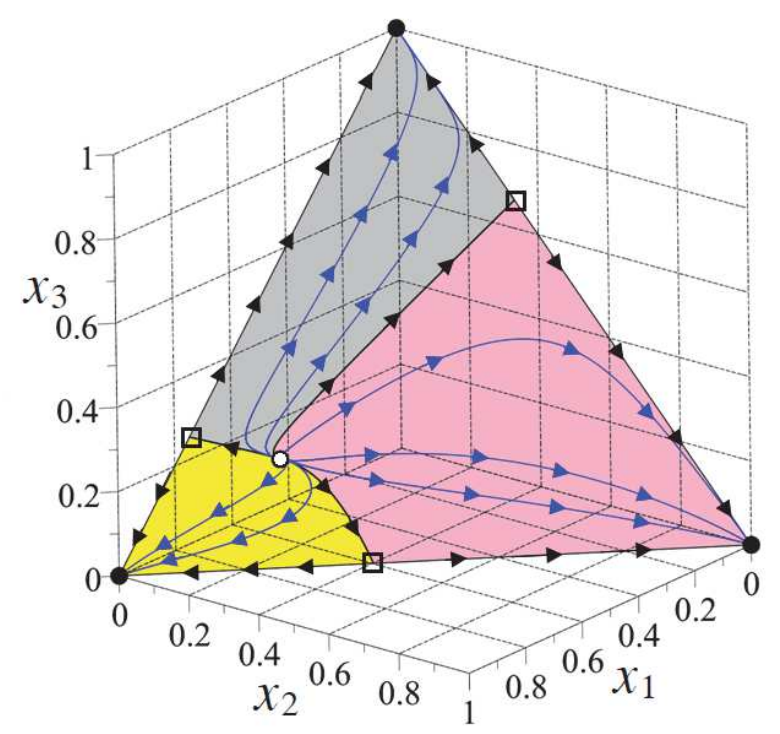

Figure 5. Case 4: All the fixed points in the vertices $e_{1}, e_{2}$ and $e_{3}$ are locally attractive.

\section{Well-being}

Matrix (2) indicates that: 1) in the vertex $e_{1}$, where everyone plays the NSP strategy $\left(x_{1}=1\right.$ and $x_{2}=x_{3}=0$ ), the NSP's payoff is $\left.\alpha ; 2\right)$ in the vertex $e_{2}$, where everyone plays the SPF strategy $\left(x_{2}=1\right.$ and $\left.x_{1}=x_{3}=0\right)$, the SPF's payoff is $\beta+\delta$; and 3 ) in the 
vertex $e_{3}$, where everyone plays the $\operatorname{SPN}$ strategy $\left(x_{3}=1\right.$ and $\left.x_{1}=x_{2}=0\right)$, the SPN's payoff is $\varepsilon+\lambda$.

Due to assumptions $V$ and $V I$, we have $\alpha<\beta+\delta$ and $\alpha<\varepsilon+\lambda$; the state $e_{1}$ where everyone plays NSP is Pareto-dominated by both $e_{2}$ and $e_{3}$.

The analysis of dynamics has shown that $e_{1}$ can be locally attractive-i.e. it may be a social poverty trap-even if there is the possibility of developing human interactions online through the SPN strategy. However, if the SPN strategy is rewarding enough in respect to NSP (i.e. $\varepsilon-\alpha-\eta \geq 0$ ), then $e_{1}$ ceases being a trap, in that it becomes a saddle point.

The state $e_{2}$, where everyone plays $S P F$, Pareto-dominates $e_{3}$, where everyone plays $S P N$, if $\beta+\delta>\varepsilon+\lambda$. If this is the case, it can be easily shown that vertex $e_{2}$ is locally attractive. This means that, in the dynamics described in Cases 1 and 3 (see Figures 2 and 4) of the previous classification, $e_{3}$ is never Pareto-dominated by $e_{2}$. However, in Cases 2 and 4 (see Figures 3 and 5), $e_{2}$ can Pareto-dominate $e_{3}$ or vice versa, even if both states are locally attractive.

In the former case, $e_{3}$ can be intended as a second-best equilibrium which, anyway, strictly Pareto-dominates $e_{1}$. In this scenario, the SPN strategy can prevent society from falling into the social poverty trap, but this entails convergence to state $e_{3}$, where all agents play $S P N$, which is Pareto-dominated by $e_{2}$ (where all agents play SPF). The configuration of parameters in the simplex's vertexes assumed in this case reflects the claims emerging from the literature reviewed in Section 2: Internet-mediated interactions play a crucial role in preventing the disruption of ties against the threats posed by mobility, sprawl, the reduction in leisure time and the decline in social participation. These interactions do not substitute for physical encounters; rather, they are complements (Cuberes, 2013). From this point of view, a state where everyone plays SPF could be equivalent, in terms of well-being, to one where all agents play SPN. However, in contrast to face-to-face interactions, online interactions may entail a number of negative consequences for individual well-being, which suggests that a state where all agents play $S P F$ may be Pareto-superior. That said, it must be remembered that the possibility of interacting online, i.e. to play SPN, wards off the worst possible state where all agents withdraw from social participation, i.e. they play NSP, and society falls into a social poverty trap.

The latter case, where $e_{2}$ and $e_{3}$ are both locally attractive and $e_{3}$ Paretodominates $e_{2}$, accounts for the more optimistic views on the effect of online interactions on social capital and well-being, and for the hypothesis that social relationships exclusively based on physical encounters may also produce negative externalities in the sense of inhibiting the diffusion of the Internet and social networks. In communities where most individuals prefer to avoid computer-mediated interactions, the diffusion of the Internet may in fact be discouraged and the risk of falling into a social poverty trap may be higher. 


\section{Conclusions}

In this paper, we draw on the empirical literature on social capital and computer-mediated communication to develop a theoretical framework analysing how human relations may evolve in a context characterised by the decline in face-to-face social participation documented by empirical studies and the rapid growth of online social participation that we have witnessed in recent years.

We assume that individuals can react to increasing busyness and the reduction in leisure time by withdrawing from social participation, or by developing a part of their social relationships online in order to overcome the barriers of distance and time. As in Antoci et al. (2012a, 2013), interpersonal interactions can be developed through two alternative forms of social participation: 1) a social networking strategy, SPN, where participation takes place both by means of online networking and face-to-face encounters; and 2) a face-to-face strategy, SPF, which is entirely developed through in-person encounters and entails no Internet-mediated interaction. In addition to the hypotheses advanced in Antoci et al. (2012a, 2013), agents can choose to withdraw from social participation and to devote all their time to work and private consumption (NSP strategy).

In a world where the only alternative to face-to-face interaction is withdrawal from participation, the state where nobody participates (i.e. all agents play NSP) is attractive, but constitutes a social poverty trap. The possibility of interacting online, on the other hand, offers an effective coping response, allowing individuals to "defend" their social life from increasing busyness and the reduction in leisure time, leading society to a state where all agents develop social interactions through a mixed strategy encompassing, to diverse extents, both physical encounters and involvement in online networks. In some cases, this is a second-best scenario that is Pareto-dominated by the state where all agents participate only through physical encounters (i.e. by playing $S P F$ ). However, the possibility of playing $S P N$ allows society to avoid the (otherwise attractive) worst-case scenario where nobody participates.

This paper represents a new step in a research programme aimed at analysing the evolution of social participation and the accumulation of social capital in relation to economic growth and technological progress. In previous works, we highlighted how the reduction in the time available for social participation can trigger self-feeding processes leading to the progressive erosion of the stock of social capital (Antoci et al., 2012b, 2013). There, we analysed a scenario in which the time for social participation is an endogenous variable (i.e. it depends on agents' allocation choices), social relationships can be developed only by means of face-to-face interaction and agents may only react to increasing busyness by replacing participation with private activities-or, in other words, to replace the production and consumption of relational goods with the production and consumption of private goods. In the present paper, we address a scenario in which agents can also interact with each other through both actual encounters and online networking. A number of relevant research questions remain unanswered and are worthy of further investigation. In our analysis, we do not advance assumptions about how face-to-face and computer-mediated interactions may be distributed within the SPN strategy

The role of online networks in the development of interpersonal relationships and in the preservation of social cohesion against the threat of social poverty traps suggest that individuals and communities who do not have access to the Internet-due, for example, to 
the absence of proper infrastructures such as broadband, or to lack of the skills required to participate in SNSs - may increasingly suffer from difficulties in social integration. In this scenario, the digital divide is likely to become an increasingly important factor of social exclusion, which may significantly exacerbate inequalities in well-being and capabilities. 


\section{A. Mathematical appendix}

We analyse dynamics (3) by using Bomze's classification (1983) for replicator equations. In order to use Bomze's classification, we need to re-write the payoff matrix (2) in the following form:

$$
A=\left(\begin{array}{lll}
0 & 0 & 0 \\
a & b & c \\
d & e & f
\end{array}\right)=\left(\begin{array}{ccc}
0 & 0 & 0 \\
\beta-\gamma-\alpha & \beta+\delta-\alpha & \beta-\alpha \\
\varepsilon-\eta-\alpha & \varepsilon-\alpha & \varepsilon+\lambda-\alpha
\end{array}\right)
$$

with the first row made of zeros. ${ }^{11}$

Remember that, according to assumptions $I-V I, \alpha, \beta, \gamma, \delta, \varepsilon, \eta, \lambda$ are strictly positive parameters satisfying the following conditions:

$$
\gamma>\eta, \quad \varepsilon-\eta>\beta-\gamma, \quad \alpha>\beta-\gamma, \quad \beta<\varepsilon+\lambda, \quad \alpha<\beta+\delta, \quad \alpha<\varepsilon+\lambda
$$

These conditions imply: $a<0, b>0, f>0, a<d, b>c, e<f, c<f$.

In this appendix, we adopt the same terminology used in Bomze (1983). By an eigenvalue EV of a fixed point we shall understand an eigenvalue of the linearization matrix around that fixed point. The term $E V$ in the direction of the vector $V$ means that $V$ is an eigenvector corresponding to that EV. IntS is the set $\left\{x \in S: x_{i}>0, i=1,2,3\right\}$ in which all strategies are present in the population. An edge of $S$ consists of all population states in which a given (fixed) strategy is not adopted; we shall denote $e_{i}-e_{j}$ the edge joining $e_{i}$ with $e_{j}$, where $e_{1}=(1,0,0), e_{2}=(0,1,0)$ and $e_{3}=(0,0,1)$ are the vectors of the canonical basis which represent the states in which only strategies NSP, SPF and SPN are played, respectively. Thus, e.g. $e_{1}-e_{2}$ is the edge where only strategies NSP and SPF are present in the population.

Let us first observe that the states in which only one strategy is adopted by individuals, $e_{i}$, are always fixed points under replicator dynamics. Their stability properties are analysed in the following proposition ${ }^{12}$. For simplicity, the propositions in Bomze (1983) will be indicated as B\# (so, e.g. B4 is Proposition 4 of Bomze's paper).

Proposition 1 The eigenvalue structure of the fixed points $\boldsymbol{e}_{i}, i=1,2,3$, is the following:

${ }^{11}$ It is a well-known result that dynamics (3) does not change if an arbitrary constant is added to each column of $A$ (see e.g. Hofbauer \& Sigmund, 1988, p. 126).

12 All the eigenvalues of the fixed points on the edges of $S$ are real (see Bomze, 1983). 
(1) $e_{1}$ has one eigenvalue with the sign of $a=\beta-\gamma-\alpha\left(<0\right.$ always) in the direction of $e_{1}-e_{2}$ and one eigenvalue with the sign of $d=\varepsilon-\eta-\alpha$ in the direction of $e_{1}-e_{3}$.

(2) $e_{2}$ has one eigenvalue with the sign of $-b=\alpha-\beta-\delta\left(<0\right.$ always) in the direction of $e_{1}-e_{2}$ and one eigenvalue with the sign of $e-b=\varepsilon-\beta-\delta$ in the direction of $e_{2}-e_{3}$.

(3) $e_{3}$ has one eigenvalue with the sign of $-f=\alpha-\varepsilon-\lambda\left(<0\right.$ always) in the direction of $e_{1}-e_{3}$ and one eigenvalue with the sign of $c-f=\beta-\varepsilon-\lambda(<0$ always $)$ in the direction of $e_{2}-e_{3}$.

Proof. Apply B1.

The following proposition concerns the fixed points on the edges of $S$.

Proposition 2 (1) A unique fixed point always exists in the interior of $e_{1}-e_{2}$. The eigenvalues of such a fixed point have the sign of $-a=-\beta+\gamma+\alpha$ (>0 always) in the direction of $e_{1}-e_{2}$ and of $(b d-a e) / b$ in the direction of the interior of $S$, where $(b d-a e) / b<0$ if and only if (iff):

$$
\begin{array}{r}
b d-a e=(\beta+\delta-\alpha)(\varepsilon-\eta-\alpha)-(\beta-\gamma-\alpha)(\varepsilon-\alpha)= \\
=-\eta(\beta+\delta-\alpha)-(\gamma+\delta)(\alpha-\varepsilon)<0
\end{array}
$$

(2) A unique fixed point exists in the interior of $e_{1}-e_{3}$ iff $d=\varepsilon-\eta-\alpha<0$; no fixed point exists if such a condition does not hold. The eigenvalues of the fixed point in the interior of $e_{1}-e_{3}$ (when existing) have the sign of $-d\left(>0\right.$ always) in the direction of $e_{1}-e_{3}$ and of $(a f-c d) / f$ in the direction of the interior of $S$, where $($ af $-c d) / f<0$ iff:

$$
\begin{gathered}
\text { af }-c d=(\beta-\gamma-\alpha)(\varepsilon+\lambda-\alpha)-(\beta-\alpha)(\varepsilon-\eta-\alpha)= \\
=-\gamma(\varepsilon+\lambda-\alpha)-(\eta+\delta)(\alpha-\beta)<0
\end{gathered}
$$

(3) $A$ unique fixed point exists in the interior of $e_{2}-e_{3}$ iff $(e-b)(f-c)=(\varepsilon-\beta-\delta)(\varepsilon+\lambda-\beta)<0$ (i.e. iff $e-b=\varepsilon-\beta-\delta<0$, being $f>c$ always); no fixed point exists if such a condition does not hold. The eigenvalues of the unique fixed point in the interior of $e_{2}-e_{3}$ have the sign of $(e-b)(f-c) /(e-b+c-f)(>0$ always) in the direction of $e_{2}-e_{3}$ and of $(b f-c e) /(e-b+c-f)$ in the direction of the interior of $S$, where $(b f-c e) /(e-b+c-f)<0$ iff:

$$
\begin{gathered}
b f-c e=(\beta+\delta-\alpha)(\varepsilon+\lambda-\alpha)-(\beta-\alpha)(\varepsilon-\alpha)= \\
=\lambda(\beta+\delta-\alpha)+\delta(\varepsilon-\alpha)>0
\end{gathered}
$$

Proof. Apply B2 and B5. 
The remaining proposition concerns the fixed points in the interior of $S$, where all strategies are adopted.

Proposition 3 There is a unique fixed point in IntS iff (see formulas (5), (6) and (7)):

$$
b f-c e>0 \quad a e-b d>0 \quad c d-a f>0
$$

If such a condition does not hold, then there are no fixed points in IntS.

Proof. According to B6, a unique fixed point in the interior of $S$ exists iff the expressions in (8) are all strictly positive or all strictly negative. A segment of non-isolated fixed points can exist only if the expressions in (8) are simultaneously equal to zero. So, to prove this proposition, we have to show that the expressions in (8) cannot be simultaneously equal to zero or strictly negative. Observe that $b f-c e \leq 0$ and $a e-b d \leq 0$ bold iff respectively:

$$
\begin{gathered}
\beta+\delta-\alpha \leq \frac{\delta(\alpha-\varepsilon)}{\lambda} \\
\beta+\delta-\alpha \leq-\frac{(\gamma+\delta)(\alpha-\varepsilon)}{\eta}
\end{gathered}
$$

Since, by assumption, $\beta+\delta-\alpha>0$, conditions (9) and (10) cannot be simultaneously satisfied. This proves the proposition.

The above propositions allow us to give a complete classification of possible dynamic regimes under dynamics (2).

Case 1: $d=\varepsilon-\alpha-\eta \geq 0$ and $e-b=\varepsilon-\beta-\delta \geq 0$

In this case, by Proposition 1, the fixed point $e_{3}$ (where all players adopt SPN) is locally attractive while $e_{1}$ and $e_{2}$ are saddle points. By Proposition 2, there is a unique fixed point in the edge $e_{1}-e_{2}$, while there are no fixed points in the edges $e_{1}-e_{3}$ and $e_{2}-e_{3}$. Since $d=\varepsilon-\alpha-\eta \geq 0$ implies $\varepsilon-\alpha>0$, the expression $b d-a e$ (see (5)) is strictly positive; therefore, the fixed point in the edge $e_{1}-e_{2}$ has two strictly positive eigenvalues, that is, it is repulsive. Looking at all possible dynamic regimes shown in Bomze (1983), it is easy to check that these properties are compatible with a unique phase portrait in Bomze's classification-phase portrait (Bpp\#, hereafter) number 4213. This dynamic regime is shown in Figure 2 of our paper.

13 When we say that a dynamic regime under equations (3) corresponds to a phase portrait Bpp\# shown in Bomze's paper, we mean that the two portraits are "geometrically equivalent" (see Bomze, 1983 , p. 205), that is, the former can be obtained from the latter by flow reversal, rotations and reflections of the simplex $S$. 
Case 2: $d=\varepsilon-\alpha-\eta \geq 0$ and $e-b=\varepsilon-\beta-\delta<0$

In this case, by Proposition 1 , the fixed points $e_{2}$ and $e_{3}$ (where all players adopt SPF and $S P N$, respectively) are locally attractive while $e_{1}$ is a saddle point. By Proposition 2 , there is a unique fixed point in the edge $e_{1}-e_{2}$ and in the edge $e_{2}-e_{3}$ while there are no fixed points in the edge $e_{1}-e_{3}$. As in Case 1 , the expression $b d-a e$ (see (5)) is strictly positive; therefore, the fixed point in the edge $e_{1}-e_{2}$ is repulsive. The unique phase portrait in Bomze's classification possessing these properties is Bpp37. This dynamic regime is shown in Figure 3 of our paper.

Case 3: $d=\varepsilon-\alpha-\eta<0$ and $e-b=\varepsilon-\beta-\delta \geq 0$

In this case, by Proposition 1 , the fixed points $e_{1}$ and $e_{3}$ are locally attractive while $e_{2}$ is repulsive; by Proposition 2, there is a unique fixed point in the edges $e_{1}-e_{2}$ and $e_{1}-e_{3}$, while no fixed point exists in $e_{2}-e_{3}$. Only Bpp9, Bpp37 and Bpp38 are compatible with these features of dynamics. In Bpp9, there exists a fixed point in the interior of $S$ (that is, condition (8) holds), which is, however, a repulsive point, and the fixed points in the edges $e_{1}-e_{2}$ and $e_{1}-e_{3}$ are saddles; the corresponding dynamic regime is illustrated in Figure 4 of our paper. In Bpp37 and Bpp38, no fixed point exists in the interior of $S$ (that is, condition (8) does not hold); in Bpp37, the fixed point in the edge $e_{1}-e_{2}$ is repulsive, while that in $e_{1}-e_{3}$ is a saddle; vice versa, in Bpp38, the stability properties of such points depend on the sign of the expressions in (8) (see Proposition 2).

Case 4: $d=\varepsilon-\alpha-\eta<0$ and $e-b=\varepsilon-\beta-\delta<0$

In this case, by Proposition 1 , all the fixed points $e_{1}, e_{2}$ and $e_{3}$ are locally attractive; by Proposition 2, there is a unique fixed point in the edges $e_{1}-e_{2}, e_{1}-e_{3}$ and $e_{2}-e_{3}$. Only Bpp7 and Bpp35 are compatible with these properties. In Bpp7, there exists a fixed point in the interior of $S$ (that is, condition (8) holds), which is, however, a repulsive point, and the fixed points in the edges $e_{1}-e_{2}, e_{1}-e_{3}$ and $e_{2}-e_{3}$ are all saddles; the corresponding dynamics is illustrated in Figure 5 of our paper. In Bpp35, no fixed point exists in the interior of $S$ (that is, condition (8) does not hold); one fixed point in the edges is repulsive while the others are saddles (the stability properties of such points depend on the sign of the expressions in (8)) — see Proposition 2).

\section{Acknowledgements}

The research of Angelo Antoci has been financed by Regione Autonoma della Sardegna (L. R. n. 7, 2007; research project: Capitale sociale e divari economici regionali). Fabio Sabatini gratefully acknowledges the support of the Laboratory for Comparative Social Research at the National Research University Higher School of Economics. 


\section{References}

Alexy, O.T., Block, J.H., Sandner, P., Ter Wal, A.L.J. (2012). Social capital of venture capitalists and start-up funding. Small Business Economics, 39:835-851.

Alloway, T.P., Horton, J., Alloway, R.G., Dawson, C. (2013). Social networking sites and cognitive abilities: Do they make you smarter? Computers \& Education, 63: 10-16.

Antoci, A., Sabatini, F., Sodini, M. (2012b). The Solaria Syndrome: Social Capital in a Hypertechnological Growing Economy. Journal of Economic Behavior and Organization 81 (3), 802-814.

Antoci, A., Sabatini, F., Sodini, M. (2013a). Bowling alone but tweeting together: the evolution of human interaction in the social networking Era. Quality \& Quantity, doi: 10.1007/s11135-013-9863-z.

Antoci, A., Sacco, P.L., Vanin, P. (2007). Social capital accumulation and the evolution of social participation. The Journal of Socio-Economics 36(1): 128-143.

Antoci, F., Sabatini, F., Sodini, M. (2012a). See You on Facebook! A framework for analyzing the role of computer-mediated interaction in the evolution of social capital. The Journal of Socio-Economics 41, 541-547.

Bartolini, S., Bilancini, E. (2011). Social Participation and Hours Worked. Department of Economics University of Siena Working Paper No. 620.

Bartolini, S., Bilancini, E., Pugno, M. (2013). Did the Decline in Social Connections Depress Americans' Happiness? Social Indicators Research, 110:1033-1059.

Bauernschuster, S., Falck, O., Woessmann, L. (2011). Surfing Alone? The Internet and Social Capital: Evidence from an Unforeseeable Technological Mistake. SOEP WP 392.

Becchetti, L., Pelloni, A., Rossetti, F. (2008). Relational Goods, Sociability, and Happiness. Kyklos 61(3): 343-363.

Besser, L. M., Marcus, M., Frumkin, H. (2008). Commute time and social capital in the U.S. American Journal of Preventing Medicine 34 (3), 207-211.

Bomze, I., 1983, Lotka-Volterra equations and replicator dynamics: a two-dimensional classification, Biological Cybernetics, 48, 201-11.

Bruni, L., Stanca, L. (2006). Income Aspirations, Television and Happiness: Evidence from the World Values Survey. Kyklos, 59 (2), 209-225. 
Bruni, L., Stanca, L. (2008). Watching alone: Relational goods, television and happiness. Journal of Economic Behavior and Organization 65 (3-4), 506-528.

Burke, M., Kraut, R., Marlow, C. (2011). Social capital on Facebook: Differentiating uses and users. ACM CHI 2011: Conference on Human Factors in Computing Systems.

Campante, F., Durante, R., Sobbrio, F. (2013). Politics 2.0: The Multifaceted Effect of Broadband Internet on Political Participation. NBER Working Paper w19029

Chou H., Edge N. (2012) 'They are happier and having better lives than I am’: The impact of using Facebook on perceptions of others' lives. Cyberpsychology, Behavior, and Social Networking, 15(2): 117-121.

Chu, Y-W., Tang, J.T.H. (2005). The Internet and Civil Society: Environmental and Labour Organizations in Hong Kong. International Journal of Urban and Regional Research, 29(4), 849866.

Clayton, R.B., Osborne, R.E., Miller, B.K., Oberle, C.D. (2013). Loneliness, anxiousness, and substance use as predictors of Facebook use. Computers in Human Behavior, 29: 687-693.

Costa, D.L., Kahn, E.M. (2003). Understanding the American decline in social capital 19521998. Kyklos 56(1), 17-46.

Cox, E. (2002). Making the Lucky Country. In: Putnam, R.D. (ed), Democracies in Flux. The Evolution of Social Capital in Contemporary Society. Oxford and New York: Oxford University Press.

Cuberes D. (2013). Are Internet and Face-to-Face Contacts Substitutes or Complements? Evidence from Internet Traffic between Cities. Sheffield Economic Research Paper Series Number: 2013010.

D’Hombres R., Rocco L., Shurcke M., Mckee M., (2010). Does social capital determine health? Evidence from eight transition countries. Health Economics 19, 56-74.

Degli Antoni G. (2009), Does satisfaction matter? A microeconomic empirical analysis on the effect of social relations on economic welfare. The Journal of Socio-Economics, 38(2): 301309.

Duggan M., Brenner J. (2013). The Demographics of Social Media Users - 2012. Washington: Pew Research Center's Internet \& American Life Project.

Ellison, N. B., Steinfield, C., Lampe, C. (2007). The benefits of Facebook friends: Social capital and college students' use of online social network sites. Journal of Computer-Mediated Communication, 12, 1143-1168. 
Ellison, N. B., Steinfield, C., Lampe, C. (2011). Connection strategies: Social capital implications of Facebook-enabled communication practices. New Media \& Society 13 (6), 873892.

Forest A.L., Wood J.V. (2012). When Social Networking Is Not Working: Individuals With Low Self-Esteem Recognize but Do Not Reap the Benefits of Self-Disclosure on Facebook. CyberPsychology, Behavior \& Social Networking, 15(2): 295-302.

Fugate, M., Kinicki, A., Ashforth, B. (2004). Employability: A psycho-social construct, its dimensions, and applications. Journal of Vocational Behavior, 65(1), 14-38.

Furlong, A. (2008). The Japanese hikikomori phenomenon: acute social withdrawal among young people. The Sociological Review, 56(2): 310-327.

Gershuny, J. 2003. Web-use and net-nerds: A neo-functionalist analysis of the impact of information technology in the home. Social Forces, 82 (1), 141-168.

Gil de Zúñiga, H., Jung, N., Valenzuela, S. (2012). Social media use for news and individuals' social capital, civic engagement and political participation. Journal of Computer-Mediated Communication, 17: 319-336.

Grieve, R., Indian, M., Witteveen, C., Tolan, G.A., Marrington, J. (2013). Face-to-face or Facebook: Can social connectedness be derived online? Computers in Human Behavior, 29: 604609.

Gui, B., Stanca, L. (2010). Happiness and relational goods: well-being and interpersonal relations in the economic sphere. International Review of Economics, 57(2): 105-118.

Gui, B., Sugden, R. (2005). Why interpersonal relations matter for economics, in: Benedetto Gui and Robert Sugden (eds.), Economics and social interactions, Accounting for Interpersonal Relations. Cambridge (Mass.): Cambridge University Press: 1-22.

Hampton, K., Wellman, B. (2003). Neighboring in Netville: How the Internet Supports Community and Social Capital in a Wired Suburb. City \& Community 2 (4), 277-311.

Hampton, K.N., Goulet, L., Rainie, L., Purcell, K. (2011). Social networking sites and our lives. Washington: Pew Research Center's Internet \& American Life Project.

Haythornthwaite, C. (2005). Social networks and Internet connectivity effects. Information, Communication \& Society, 8, 125-147.

Hofbauer J., 1981, On the Occurrence of Limit Cycles in the Volterra-Lotka Equation, Nonlinear Analysis. Theory, Methods and Applications, 5, 1003-1007. 
Hofbauer, J., Sigmund, K., 1988, The Theory of Evolution and Dynamical Systems, Cambridge, Cambridge University Press.

Kaneko, S. (2006). Japan's 'Socially Withdrawn Youths' and Time Constraints in Japanese Society. Time \& Society, 15(2-3): 233-249.

Kato, T., Tateno, M., Shinfuku, N., Fujisawa, D., Teo, A.R., Sartorius, N., Akiyama, T., Tetsuda, I., Choi, T.Y., Balhara, Y.P.S., Matsumoto, R., Umene-Nakano, U., Fujimura, Y., Wand, A., Chang, J.P-C., Chang R., Y.-F., Shadloo, B., Ahmed H.U., Lerthattasilp, T., Kanba, S. (2012). Does the 'hikikomori' syndrome of social withdrawal exist outside Japan? A preliminary international investigation. Social Psychiatry and Psychiatric Epidemiology, 47: 10611075.

Katz, J., Rice, R. E., Apsden, P. (2001). The Internet, 1995-2000: Access, Civic Involvement and Social Interaction. American Behavioral Scientist 45, 405-419.

Kim J, LaRose R, Peng W (2009). Loneliness as the cause and the effect of problematic Internet use: the relationship between Internet use and psychological well-being. CyberPsychology \& Bebavior, 12(4): 451-455.

Kittikson, M.C., Dalton, R.J. (2011). Virtual Civil Society: The New Frontier of Social Capital? Political Behavior, 33: 625-644.

Knack, S., Keefer, P. (1997). Does Social Capital Have an Economic Payoff? A CrossCountry Investigation. Quarterly Journal of Economics 112 (4): 1251-1288.

Lee, D.Y. (2013). The role of attachment style in building social capital from a social networking site: The interplay of anxiety and avoidance. Computers in Human Behavior, 29: 1499-1509.

Lee, J. (2008). Unravelling the dynamics and trends of social capital: Case of South Korea. Asian Journal of Social Psycbology, 11: 105-115.

Leigh, A. (2003). Entry on "Trends in Social Capital", prepared for Karen Christensen and David Levinson (eds) (2003) Encyclopedia of Community: From the Village to the Virtual World. Thousand Oaks, CA: Sage.

Listhaug, O., Grønflaten, L. (2007). Civic Decline? Trends in Political Involvement and Participation in Norway, 1965-2001. Scandinavian Political Studies, 30(2): 272-299.

McDonald, S. (2011). What You Know or Who You Know? Occupation-specific work experience and job matching through social networks. Social Science Research, 40: 1664-1675.

Misra, K., Grimes, P.W., Rogers, K.E. (2013). The effects of community social capital on school performance: A spatial approach. The Journal of Socio-Economics, 42: 106-111. 
Morahan-Martin, J., Schumacher, P. (2003). Loneliness and social uses of the Internet. Computers in Human Behavior, 19: 659-671.

Nagler, M.G. (2013). Does social capital promote safety on the roads? Economic Inquiry, 52(2), $1218-1231$.

Näsi, M., Räsänen, P., Sarpila, O. (2012). ICT activity in later life: Internet use and leisure activities amongst senior citizens in Finland. European Journal of Ageing, 9: 169-176.

Nie, N. H., Sunshine Hillygus D., Erbring, L. (2002). Internet Use, Interpersonal Relations and Sociability: A Time Diary Study. In Wellman, B., Haythornthwaite, C. (eds). The Internet in Everyday Life. Oxford: Blackwell, pp. 215-243.

Olson, M. (1965). The Logic of Collective Action: Public Goods and the Theory of Groups, Cambridge: Harvard University Press.

Olson, M. (1982). The Rise and Decline of Nations: Economic Growth, Stagflation, and Social Rigidities. Yale: Yale University Press.

Paxton, P. (1999). Is Social Capital Declining in the United States? A Multiple Indicator Assessment. American Journal of Sociology, 105(1): 88-127.

Pénard, T., Poussing, N. (2010). Internet Use and Social Capital: The Strength of Virtual Ties. Journal of Economic Issues 44 (3), 569-595.

Putnam, R. D. (2000). Bowling Alone: The Collapse and Revival of American Community. New York: Simon \& Schuster.

Putnam, R.D. (2002). Democracies in Flux. The Evolution of Social Capital in Contemporary Society. Oxford and New York: Oxford University Press.

Routledge, B.R., von Amsberg, J. (2002). Social Capital and Growth. Journal of Monetary Economics 50 (1), 167-193.

Russel, C., Cambell, A., Hughes, I. (2008). Ageing, social capital and the Internet: Findings from an exploratory study of Australian 'silver surfers'. Australasian Journal on Ageing, 27(2): $78-82$.

Santarelli, E., Tran, H.T. (2013). The interplay of human and social capital in shaping entrepreneurial performance: the case of Vietnam. Small Business Economics, 40:435-458.

Sabatini, F., Sarracino, F. (2014). Will Facebook save or destroy social capital? An empirical investigation into the effect of online interactions on trust and networks. GESIS Working Paper No 2014/30. Leibniz Institute for the Social Sciences. 
Sarracino, F. (2010). Social capital and subjective well-being trends: Comparing 11 western European countries. The Journal of Socio-Economics 39(4): 482-517.

Shoji, M., Aoyagi, K., Kasahara, R., Sawada, Y., Ueyama, M. (2012). Social Capital Formation and Credit Access: Evidence from Sri Lanka. World Development, 40(12), 2522-2536.

Smith, A. (2013). Civic Engagement in the Digital Age. Washington: Pew Research Center's Internet \& American Life Project.

Steinfield, C., Ellison, N.B., Lampe, C. (2008). Social capital, self-esteem, and use of online social network sites: A longitudinal analysis. Journal of Applied Developmental Psychology, 29: 434445 .

Stolle, D., Hooghe, M. (2005). Inaccurate, Exceptional, One-Sided or Irrelevant? The Debate about the Alleged Decline of Social Capital and Civic Engagement in Western Societies. British Journal of Political Science, 35(1): 149-167.

Taylor P., Yonker L., 1978, Evolutionary stable strategies and game dynamics, Mathematical Biosciences, 40, 145-56.

Trepte, S., Reinecke, L. (2013). The reciprocal effects of social network site use and the disposition for self-disclosure: A longitudinal study. Computers in Human Behavior, 29: 11021112.

Uhlaner, C. J. (1989). Relational Goods and Participation: Incorporating Sociability into a Theory of Rational Action. Public Choice 62, 253-285.

Valenzuela, S., Park, N., Kee, K.F. (2009). Is There Social Capital in a Social Network Site?: Facebook Use and College Students' Life Satisfaction, Trust, and Participation. Journal of Computer-Mediated Communication, 14: 875-901.

Van Ingen, E., Dekker, P. (2011). Dissolution of Associational Life? Testing the Individualization and Informalization Hypotheses on Leisure Activities in The Netherlands Between 1975 and 2005. Social Indicators Research, 100: 209-224.

Weibull, J.W., 1995, Evolutionary Game Theory, Cambridge (Ma.), MIT Press.

Wollebæk, D., Strømsnes, K. (2011). presented at the 9th International Conference of the International Society for Third-Sector Research (ISTR), July 7-10, Kadir Has University, Istanbul, Turkey.

Worms, J.-P. (2002). Old and New Civic and Social Ties in France. In: Putnam, R.D. (ed), Democracies in Flux. The Evolution of Social Capital in Contemporary Society. Oxford and New York: Oxford University Press. 
Yamamura, E. (2011a). Different effects of social capital on health status among residents: Evidence from modern Japan. The Journal of Socio-Economics, 40(5): 475-479.

Yamamura, E. (2011b). The role of social trust in reducing long-term truancy and forming human capital in Japan. Economics of Education Review, 30(2): 380-389.

Yamamura, E. (2012). Social capital, household income, and preferences for income redistribution. European Journal of Political Economy, 28(4): 498-511.

Zhang, W., Johnson, T. J., Seltzer, T., Bichard, S. L. (2010). The Revolution Will be Networked. The Influence of Social Networking Sites on Political Attitudes and Behavior. Social Science Computer Review 28 (1), 75-92. 